\title{
Splenic Follicular Lymphoma
}

National Cancer Institute

\section{Source}

National Cancer Institute. Splenic Follicular Lymphoma. NCI Thesaurus. Code C7307.

A follicular lymphoma occurring in the spleen. 